\title{
Peripheral artery disease and osteoporosis: Not only age-related (Review)
}

\author{
AGOSTINO GAUDIO, ANASTASIA XOURAFA, ROSARIO RAPISARDA, \\ PIETRO CASTELLINO and SALVATORE SANTO SIGNORELLI
}

Department of Clinical and Experimental Medicine, University of Catania, University Hospital 'G. Rodolico', I-95123 Catania, Italy

Received June 1, 2018; Accepted July 11, 2018

DOI: $10.3892 / \mathrm{mmr} .2018 .9512$

\begin{abstract}
Osteoporosis and atherosclerosis are two chronic degenerative diseases that share several biochemical pathways and risk factors. Previous studies have associated osteoporosis with carotid atherosclerosis, cardiovascular mortality and stroke, but data on the relationship with peripheral artery disease are few and conflicting. The OPG/RANK/RANKL system and Wnt/beta catenin signaling seem to be deeply involved in the pathogenesis of bone alterations and atherosclerotic processes also affect arteries of the lower extremities. Hypovitaminosis D could also play a role in the relationship of these two diseases. New and larger studies are necessary to shed light on this association and to design new drugs able to act in both these chronic degenerative diseases.
\end{abstract}

\section{Contents}

1. Introduction

2. Atherosclerosis and osteoporosis

3. Methods

4. Peripheral artery disease (PAD) and osteoporosis: Epidemiological data

5. Peripheral artery disease (PAD) and osteoporosis: Possible common pathogenic factors

6. Conclusion

\section{Introduction}

Occlusive atherothrombotic diseases occur in different vascular territories such as in coronary, carotid and peripheral arteries.

Correspondence to: Professor Salvatore Santo Signorelli, Department of Clinical and Experimental Medicine, University of Catania, University Hospital ‘G. Rodolico', Via S. Sofia 78, I-95123 Catania, Italy E-mail: ssignore@unict.it

Key words: PAD, osteoporosis, osteoprotegerin, sclerostin, hypovitaminosis D
The consequent diseases such as coronary heart diseases (CHD), carotid disease (CD) and peripheral artery disease (PAD) may be considered cardiovascular killers. In general, cardiovascular diseases have mostly been investigated for prevalence, frequency, pathophysiology, outcome and prevention, but PAD is not sufficiently considered compared to other diseases (1-3). There are discordant results on PAD epidemiology but they derive from different study populations (hospitalized, general) or from different diagnostic methods (clinical, instrumental, discharge code). However, effective epidemiological data are derived from the use of the ankle-brachial index (ABI) to diagnose PAD (4-7). To the best of our knowledge, the prevalence of PAD in advanced countries ranges from 3 to $10 \%$ in individuals aged 40-70 years, and 10-20\% in individuals over 70 years of age (8-14) (Table I). The prevalence of PAD is the same in men and women, whereas ABI is higher in women (10.6 vs. $4.3 \%)$ (15). Similarly, both diabetics and regular smokers show a higher prevalence of PAD (1,3,10-15). The number of elderly people has tripled during the last 50 years and therefore the number of patients with PAD has increased. Secondly, PAD patients have been diagnosed more frequently in hospital where there is greater awareness about managing them according to guidelines for the secondary prevention of cardiovascular events, improvement in physical performance, clinical symptoms and improvement in the quality of life. Data provided following a global estimation of PAD prevalence show that, 202 million individuals are affected by this occlusive artery disease, but it is very interesting to note an increase of 23.5\% in PAD diagnoses from 2000 to 2010 (7). PAD has become a serious medical and social issue. However, PAD is underrecognized although it may easily be diagnosed by using a handle pocket Doppler to measure ABI. PAD is also undertreated because its clinical signals (i.e., intermittent claudication) often do not appear in older individuals or those leading a sedentary lifestyle (16-20).

\section{Atherosclerosis and osteoporosis}

Osteoporosis and atherosclerosis are two chronic degenerative diseases whose incidence increases with age. At present, mounting evidence indicates a relationship between cardiovascular disease and osteoporosis, regardless of age. These seem to have many common biochemical pathways and risk factors. 
In addition, the mechanism of arterial calcification is similar to the process of osteogenesis, involving various cells, proteins and cytokines, which lead to tissue mineralization (21). Due to these strict interconnections, the drugs used for osteoporosis treatment (vitamin D, estradiol, and bisphosphonates) may interfere with vessel wall processes. On the other hand, several of the drugs used to treat cardiovascular diseases (statins, antihypertensives, warfarin, and heparins) may affect bone tissue metabolism (22).

Previous studies have associated osteoporosis with cardiovascular mortality $(23,24)$, aortic and coronary calcification $(25,26)$, carotid atherosclerosis $(27)$, and stroke (28) in men and women, particularly the latter. There are little data available on the relationship between osteoporosis and PAD.

\section{Methods}

A literature search was conducted to identify studies published in English language journals since 1990 concerning the relationship between osteoporosis and PAD. The MEDLINE electronic database was used to identify potential studies. The MEDLINE search terms included peripheral artery disease and osteoporosis or bone turnover markers, osteoprotegerin and sclerostin.

\section{Peripheral artery disease and osteoporosis: Epidemiological data}

The data associating PAD and osteoporosis are conflicting. The osteodensitometric evaluation by Fehérvári et al (29) found $37 \%$ of patients with lower limb ischemia had osteopenia and $31 \%$ had osteoporosis, with significantly more females than males having osteoporosis. Most recently, Baldwin et al (30) found that osteopenia and osteoporosis are independent risk factors for PAD in both males and female. The data agree with previous results showing an increased prevalence of PAD in osteoporotic postmenopausal women (31).

In a large prospective cohort of 3,998 Chinese men and women (65-92 years of age) in Hong Kong, the ABI correlated positively with hip BMD (correlation coefficient $=0.27$; $\mathrm{P}<0.001)$. However, after adjustment for confounding factors, the correlation became much weaker (correlation coefficient $=0.03 ; \mathrm{P}<0.05)(32)$.

The Rotterdam Study (3,053 women and 2,215 men) associated low femoral neck BMD and PAD in women only. By contrast, lumbar spine BMD and PAD were not associated in either men or women (33).

Pasqualini et al (34), reported that hypovitaminosis D and increased bone turnover were risk factors for PAD and its severity. However, the presence of PAD even if asymptomatic and diagnosed by a lowered ABI could identify a population at risk of osteoporosis.

Fehérvári et al (35) found a connection between the severity of atherosclerosis and osteoporosis in patients with PAD, specific to the site of the lesion. In patients with iliac disease, a Bollinger angiographic score (BS, a method of PAD classification according to the occlusive pattern) was associated with lumbar-BMD and with femoral-BMD. These findings support the hypothesis that reduced blood flow is the key factor in the inverse association of BMD with atherosclerosis.
During an average 4-year follow-up, women with PAD had a significantly higher rate of bone loss than women without PAD $(\mathrm{P}=0.05)$. By contrast, PAD was not associated in men with osteoporosis, but men with PAD had lower BMD at the femoral neck than men without PAD $(\mathrm{P}=0.03)$. PAD was not associated with osteoporotic fractures in either males or females (36).

\section{Peripheral artery disease and osteoporosis: Possible common pathogenic factors}

Osteoprotegerin (OPG), a member of the tumor necrosis factor receptor family, is involved in the process of bone turnover and in the pathogenesis of osteoporosis and premature calcification of the vascular system (37).

Few data are available associating serum OPG plasma levels with PAD or its severity. Ziegler et al (38), reported that plasma OPG concentrations were significantly higher in subjects with PAD undergoing percutaneous transluminal angioplasty (PTA) because of advanced clinical stages III-IV than in patients without ischemic ulcerations. In addition, OPG correlated positively with BS of disease, age and creatinine values and correlated negatively with $\mathrm{ABI}$.

Those data conflict with our results, which found similar serum OPG and RANKL levels in PAD patients and controls. We concluded there was no increased activation of the OPG-RANKL system (39).

Recently, Demková et al (40), confirmed that OPG levels were significantly higher in patients with PAD than patients without PAD. Additionally, serum OPG levels were associated significantly with PAD and its severity in patients with T2DM. Those data suggest that OPG may be a biomarker for atherosclerosis in patients with T2DM.

The role of OPG as a marker of arterial consequences in diabetic patients particularly in PAD subjects has been previously reported. Esteghamati et al (41) reported that in patients with T2DM for $>5$ years without apparent diabetic foot ulcer, one standard deviation increase in log-osteoprotegerin was associated with a $>2$-fold increase in the risk of having PAD (odds ratio 2.26, 95\% confidence interval 1.50-3.40). In addition, in type 1 diabetes, OPG levels were associated with the development of foot ulcer, even after comprehensive adjustment (42).

OPG is not only important in diabetic patients. In fact, $\mathrm{O}^{\prime}$ Sullivan observed that PAD is associated with higher serum OPG, regardless of the co-existence of DM (43).

In a systematic review, it was found that OPG is a marker of atherosclerosis. OPG concentrations were associated with stable coronary artery disease and its severity, acute coronary syndrome, and cerebrovascular disease but no association was found between PAD and OPG concentrations (44).

However, another recent review reported eight studies showing correlations between OPG levels and PAD, its progression and severity, whereas just one study did not find OPG levels significantly higher. The authors concluded that the results from clinical and experimental research on the role of vascular calcification markers in PAD are controversial, although most studies suggest a positive correlation (45).

Further studies are required to analyze the role of OPG as a diagnostic marker for the severity of atherosclerosis particularly in PAD patients. 
Table I. Number of studies on the prevalence of PAD in general and in hospitalized populations.

\begin{tabular}{|c|c|c|c|c|}
\hline Author & Prevalence $(\%)$ & Subjects & Study population & (Refs.) \\
\hline Murabito et al, 2002 & 3.9 (male) 3.3 (female) & 3,313 & Population-based & (3) \\
\hline Selvin et al, 2004 & 4.3 & 2,174 & From National Survey (NHANES) & $(8)$ \\
\hline Mostaza et al, 2008 & $\begin{array}{l}\text { a) } 33.8 \\
\text { b) } 32.4 \\
\text { c) } 53.9\end{array}$ & 1,203 & $\begin{array}{l}\text { Internal medicine outpatients with: } \\
\text { a) previous coronary event, } \\
\text { b) cerebrovascular disease } \\
\text { c) disease in both territories }\end{array}$ & (11) \\
\hline Ramos et al, 2009 & 4.5 & 6,262 & Population-based cross-sectional survey & (12) \\
\hline Alzamora et al, 2010 & 7.6 & 3,786 & Population-based & (13) \\
\hline Santo Signorelli et al, 2010 & 2.3 & 3,412 & Population-based from general physicians files & $(19)$ \\
\hline
\end{tabular}
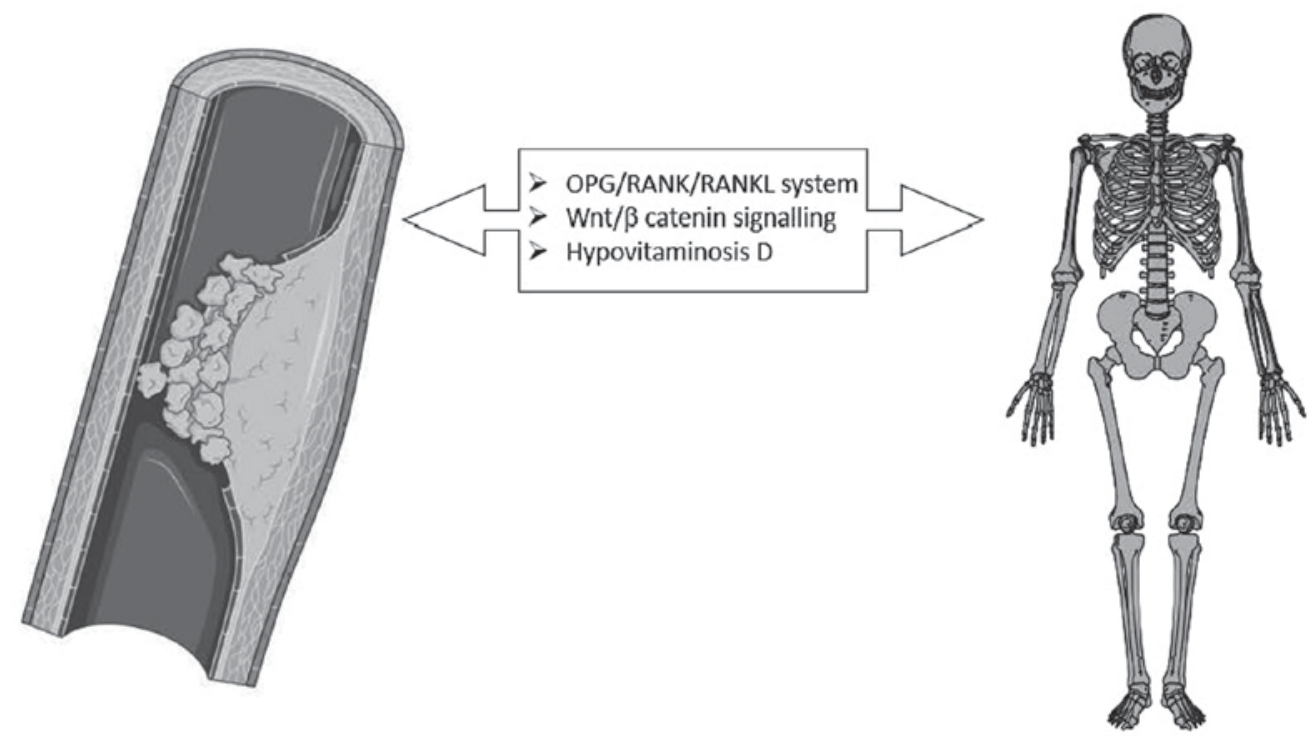

Figure 1. Figure summarizes the possible pathogenetic links between PAD and osteoporosis.

Ye et al (46), suggested that a multi-marker approach may improve the inter-individual prediction of variation in $\mathrm{ABI}$ and it may be useful in predicting PAD. In particular, those authors evaluated biomarkers including C-reactive protein, interleukin-6, tumor necrosis factor receptor-II, lipoprotein(a), $\mathrm{N}$-terminal pro-brain natriuretic peptide, pro-atrial natriuretic peptide, C-terminal pro-arginine vasopressin, osteoprotegerin, and fibrinogen in African-Americans and non-Hispanic whites. It was suggested that different factors could play a pathogenetic role for osteoporosis and PAD, particularly data on hypovitaminosis D.

Hypovitaminosis D is frequent in patients with PAD. Secondary hyperparathyroidism and osteomalacia as consequences may contribute to bone pain and myalgias, and worsen clinical symptoms of PAD such as intermittent claudication (47).

In the last decade, canonical Wnt/beta signaling has been shown to play a significant role in the control of osteoblastogenesis and bone formation. This signaling is finely controlled via several soluble inhibitors such as sclerostin and DKK-1. There is some evidence of a possible role for Wnt/beta signaling in atherosclerosis, but data on PAD patients are insufficient (48).

Sclerostin and Dkk-1 are two soluble inhibitors of Wnt/beta signaling associated with acute ischemic stroke (49).

In an animal model, upregulating SOST (gene coding for sclerostin) inhibits aortic aneurism and atherosclerosis development with potentially important implications for treating these vascular diseases (50).

In subjects with coronary artery disease who underwent CABG (coronary artery bypass graft), serum sclerostin levels were higher compared to controls (51).

In a previous study, we showed that, following adjustment for confounders, sclerostin is an independent predictor of arterial stiffness in the outpatient population (52). Sclerostin may serve as a useful biomarker for early atherosclerosis in obese individuals without a previous history of cardiometabolic disorders but this requires further testing (53).

Morales-Santana et al (54) produced some interesting results on sclerostin circulating levels in T2DM patients with atherosclerotic lesions. Authors of that study found higher 
circulating sclerostin levels, and a significant negative correlation between sclerostin and other bone markers such as DKK-1 with intima-media thickness of the carotid artery (CIMT) (55). Based on those data, sclerostin may protect against arterial consequences in T2DM, possibly by attenuating the upregulation of $\beta$-catenin activity in vascular cells. Romosozumab is a monoclonal antibody that binds to and inhibits sclerostin, increasing bone formation and decreasing bone resorption. In a recent trial conducted on post-menopausal women, serious adverse cardiovascular events were observed more often with romosozumab than with alendronate (56). The findings support our hypothesis of a protective role for sclerostin in atherosclerosis.

\section{Conclusion}

A large amount of data support, over an age-related association between PAD and atherosclerosis, a possible sharing of common pathogenetic links. In particular, the OPG/RANK/RANKL system and Wnt/beta catenin signaling seem to be deeply involved in the pathogenesis of bone alterations and atherosclerotic processes also affecting the arteries of the lower extremities (Fig. 1). The complete comprehension of these common pathways, through future studies, could be extremely important in the designing of future innovative drugs able to protect both arterial walls and bone.

\section{Acknowledgements}

Not applicable.

\section{Funding}

No funding was received.

\section{Availability of data and materials}

Not applicable.

\section{Authors' contributions}

Authors contributed both in searching and in writing the present review. AG, AX and RR were highly endorsed in publications search from the literature database. SS and AG wrote the review. AG, AX, RR, PC and SS revised it critically for important intellectual content and approved the version to be published. All authors read and approved the manuscript.

\section{Ethics approval and consent to participate}

Not applicable.

\section{Patient consent for publication}

Not applicable.

\section{Competing interests}

The authors declare that they have no competing interests.

\section{References}

1. Hirsch AT, Haskal ZJ, Hertzer NR, Bakal CW, Creager MA, Halperin JL, Hiratzka LF, Murphy WR, Olin JW, Puschett JB, et al: ACC/AHA 2005 Practice Guidelines for the management of patients with peripheral arterial disease (lower extremity, renal, mesenteric, and abdominal aortic): A collaborative report from the American association for vascular surgery/society for vascular surgery, society for cardiovascular angiography and interventions, society for vascular medicine and biology, society of interventional radiology and the ACC/AHA task force on practice guidelines (Writing Committee to Develop Guidelines for the Management of Patients With Peripheral Arterial Disease): Endorsed by the American association of cardiovascular and pulmonary rehabilitation; national heart, lung, and blood institute; society for vascular nursing; transatlantic inter-society consensus; and vascular disease foundation. Circulation 113: e463-e654, 2006.

2. Greenland P, Abrams J, Aurigemma GP, Bond MG, Clark LT, Criqui MH, Crouse JR III, Friedman L, Fuster V, Herrington DM, et al: Prevention conference V: Beyond secondary prevention: Identifying the high-risk patient for primary prevention: Noninvasive tests of atherosclerotic burden: Writing Group III. Circulation 101: E16-E22, 2000.

3. Murabito JM, Evans JC, Nieto K, Larson MG, Levy D and Wilson PW: Prevalence and clinical correlates of peripheral arterial disease in the Framingham offspring study. Am Heart J 143: 961-965, 2002.

4. Newman AB, Siscovick DS, Manolio TA, Polak J, Fried LP, Borhani NO and Wolfson SK: Ankle-arm index as a marker of atherosclerosis in the Cardiovascular health study. Cardiovascular heart study (CHS) collaborative research group. Circulation 88: $837-845,1993$.

5. Doobay AV and Anand SS: Sensitivity and specificity of the ankle-brachial index to predict future cardiovascular outcomes: A systematic review. Arterioscler Thromb Vasc Biol 25: 1463-1469, 2005

6. Xu D, Zou L, Xing Y, Hou L, Wei Y, Zhang J, Qiao Y, Hu D, $\mathrm{Xu}$ Y, Li J and Ma Y: Diagnostic value of ankle-brachial index in peripheral arterial disease: A meta-analysis. Can J Cardiol 29: 492-498, 2013.

7. Fowkes FG, Rudan D, Rudan I, Aboyans V, Denenberg JO, McDermott MM, Norman PE, Sampson UK, Williams LJ, Mensah GA and Criqui MH: Comparison of global estimates of prevalence and risk factors for peripheral artery disease in 2000 and 2010: A systematic review and analysis. Lancet 382: 1329-1340, 2013.

8. Selvin E and Erlinger TP: Prevalence of and risk factors for peripheral arterial disease in the United States: Results from the national health and nutrition examination survey, 1999-2000. Circulation 110: 738-743, 2004.

9. Carbayo JA, Divisón JA, Escribano J, López-Abril J, López de Coca E, Artigao LM, Martínez E, Sanchis C, Massó J and Carrión L; Grupo de Enfermedades Vasculares de Albacete (GEVA): Using anklebrachial index to detect peripheral arterial disease: Prevalence and associated risk factors in a random population sample. Nutr Metab Cardiovasc Dis 17: 41-49, 2007.

10. Sigvant B, Wiberg-Hedman K, Bergqvist D, Rolandsson O, Andersson B, Persson E and Wahlberg E: A population-based study of peripheral arterial disease prevalence with special focus on critical limb ischemia and sex differences. J Vasc Surg 45: 1185-1191, 2007.

11. Mostaza JM, Manzano L, Suárez C, Cairols M, Ferreira EM, Rovira E, Sánchez A, Suárez-Tembra MA, Estirado E, Estrella Jde D, et al: Prevalence of asymptomatic peripheral artery disease detected by the ankle-brachial index in patients with cardiovascular disease. MERITO II study). Med Clin (Barc) 131: $561-565,2008$

12. Ramos R, Quesada M, Solanas P, Subirana I, Sala J, Vila J, Masiá R, Cerezo C, Elosua R, Grau M, et al: Prevalence of symptomatic and asymptomatic peripheral arterial disease and the value of the ankle-brachial index to stratify cardiovascular risk. Eur J Vasc Endovasc Surg 38: 305-311, 2009.

13. Alzamora MT, ForeÂs R, Baena-DõÂez JM, Pera G, Toran P, Sorribes M, Vicheto M, Reina MD, Sancho A, Albaladejo C, et al: The peripheral arterial disease study (PERART/ARTPER): Prevalence and risk factors in the general population. BMC Public Health 10: 38, 2010. 
14. Aboyans V, Criqui MH, Abraham P, Allison MA, Creager MA Diehm C, Fowkes FG, Hiatt WR, Jönsson B, Lacroix P, et al: Measurement and interpretation of the ankle-brachial index: A scientific statement from the American heart association. Circulation 126: 2890-2909, 2012.

15. Fowkes FG, Rudan D, Rudan I, Aboyans V, Denenberg JO, McDermott MM, Norman PE, Sampson UK, Williams LJ, Mensah GA and Criqui MH: Comparison of global estimates of prevalence and risk factors for peripheral artery disease in 2000 and 2010: A systematic review and analysis. Lancet 382: $1329-1340,2013$

16. Wilkins JT, McDermott MM, Liu K, Chan C, Criqui MH and Lloyd-Jones DM: Associations of noninvasive measures of arterial compliance and ankle-brachial index: The multi-ethnic study of atherosclerosis (MESA). Am J Hypertens 25: 535-541, 2012.

17. Hiatt WR: Medical treatment of peripheral arterial disease and claudication. N Engl J Med 344: 1608-1621, 2001.

18. Watson K, Watson BD and Pater KS: Peripheral arterial disease: A review of disease awareness and management. Am J Geriatr Pharmacother 4: 365-379, 2006.

19. Santo Signorelli S, Anzaldi M, Fiore V, Catanzaro S, Simili M, Torrisi B and Neri S: Study on unrecognized peripheral arterial disease (PAD) by ankle/brachial index and arterial comorbidity in Catania, Sicily, Italy. Angiology 61: 524-529, 2010.

20. Signorelli SS, Fiore V, Catanzaro S, Simili M, Torrisi B and Anzaldi M: Prevalence of high ankle-brachial index (ABI) in general population of Southern Italy, risk factor profiles and systemic cardiovascular co-morbidity: An epidemiological study. Arch Gerontol Geriatr 53: 55-59, 2011.

21. Danilevicius CF, Lopes JB and Pereira RM: Bone metabolism and vascular calcification. Braz J Med Biol Res 40: 435-442, 2007.

22. Karwowski W, Naumnik B, Szczepański M and Myśliwiec M: The mechanism of vascular calcification-a systematic review. Med Sci Monit 18: RA1-RA11, 2012.

23. Sennerby U, Farahmand B, Ahlbom A, Ljunghall S and Michaëlsson K: Cardiovascular diseases and future risk of hip fracture in women. Osteoporos Int 18: 1355-1362, 2007.

24. Marcovitz PA, Tran HH, Franklin BA, O'Neill WW, Yerkey M, Boura J, Kleerekoper M and Dickinson CZ: Usefulness of bone mineral density to predict significant coronary artery disease. Am J Cardiol 96: 1059-1063, 2005.

25. Kiel DP, Kauppila LI, Cupples LA, Hannan MT, O'Donnell CJ and Wilson PW: Bone loss and the progression of abdominal aortic calcification over a 25 year period: The Framingham heart study. Calcif Tissue Int 68: 271-276, 2001

26. Barengolts EI, Berman M, Kukreja SC, Kouznetsova T, Lin C and Chomka EV: Osteoporosis and coronary atherosclerosis in asymptomatic postmenopausal women. Calcif Tissue Int 62: 209-213, 1998.

27. Jorgensen L, Joakimsen O, Mathiesen EB. Ahmed L, Berntsen GK, Fønnebø V, Joakimsen R, Njølstad I, Schirmer H and Jacobsen BK: Carotid plaque echogenicity and risk of nonvertebral fractures in women: A longitudinal population-based study. Calcif Tissue Int 79: 207-213, 2006.

28. Jørgensen L, Engstad T and Jacobsen BK: Bone mineral density in acute stroke patients: Low bone mineral density may predict first stroke in women. Stroke 32: 47-51, 2001

29. Fehérvári M, Krepuska M, Csobay-Novák C, Lakatos P, Oláh Z, Acsády G and Szeberin Z: Prevalence of osteoporosis in patients with severe peripheral artery disease. Orv Hetil 154: 369-375, 2013.

30. Baldwin MJ, Policha A, Maldonado T, Hiramoto JS, Honig S, Conte MS, Berger J and Rockman CB: Novel association between bone mineral density scores and the prevalence of peripheral artery disease in both sexes. Vasc Med 22: 13-20, 2017.

31. Mangiafico RA, Russo E, Riccobene S, Pennisi P, Mangiafico M, D'Amico F and Fiore CE: Increased prevalence of periphera arterial disease in osteoporotic postmenopausal women. J Bone Miner Metab 24: 125-131, 2006

32. Wong SY, Kwok T, Woo J, Lynn H, Griffith JF, Leung J, Tang YY and Leung PC: Bone mineral density and the risk of periphera arterial disease in men and women: Results from Mr. and Ms Os, Hong Kong. Osteoporos Int 16: 1933-1938, 2005.

33. van der Klift M, Pols HA, Hak AE, Witteman JC, Hofman A and de Laet CE: Bone mineral density and the risk of peripheral arterial disease: The rotterdam study. Calcif Tissue Int 70: 443-449, 2002.
34. Pasqualini L, Ministrini S, Macura A, Marini E, Leli C, Siepi D, Lombardini R, Kararoudi MN, Scarponi AM, Schillaci G, et al: Increased bone resorption: A possible pathophysiological link between hypovitaminosis D and peripheral arterial disease. Eur J Vasc Endovasc Surg 52: 352-359, 2016.

35. Fehérvári M, Sarkadi H, Krepuska M, Sótonyi P, Acsády G, Entz L, Lakatos P and Szeberin Z: Bone mineral density is associated with site-specific atherosclerosis in patients with severe peripheral artery disease. Calcif Tissue Int 93: 55-61, 2013.

36. von Mühlen D, Allison M, Jassal SK and Barrett-Connor E: Peripheral arterial disease and osteoporosis in older adults: The rancho bernardo study. Osteoporos Int 20: 2071-2018, 2009.

37. Hsu H, Lacey DL, Dunstan CR, Solovyev I, Colombero A, Timms E, Tan HL, Elliott G, Kelley MJ, Sarosi I, et al: Tumor necrosis factor receptor family member RANK mediates osteoclast differentiation and activation induced by osteoprotegerin ligand. Proc Natl Acad Sci USA 96: 3540-3545, 1999.

38. Ziegler S, Kudlacek S, Luger A and Minar E: Osteoprotegerin plasma concentrations correlate with severity of peripheral artery disease. Atherosclerosis 182: 175-180, 2005.

39. Pennisi P, Signorelli SS, Riccobene S, Celotta G, Di Pino L, La Malfa $\mathrm{T}$ and Fiore CE: Low bone density and abnormal bone turnover in patients with atherosclerosis of peripheral vessels. Osteoporos Int 15: 389-395, 2004

40. Demková K, Kozárová M, Malachovská Z, Javorský M and Tkáč I: Osteoprotegerin concentration is associated with the presence and severity of peripheral arterial disease in type 2 diabetes mellitus. Vasa 47: 131-135, 2018.

41. Esteghamati A, Aflatoonian M, Rad MV, Mazaheri T, Mousavizadeh M, Nakhjavani M and Noshad S: Association of osteoprotegerin with peripheral artery disease in patients with type 2 diabetes. Arch Cardiovasc Dis 108: 412-419, 2015.

42. Zobel EH, von Scholten BJ, Lajer M, Jorsal A, Tarnow L, Rasmussen LM, Holstein P, Parving HH, Hansen TW and Rossing P: High osteoprotegerin is associated with development of foot ulcer in type 1 diabetes. J Diabetes Complications 30: 1603-1608, 2016.

43. O'Sullivan EP, Ashley DT, Davenport C, Kelly J, Devlin N, Crowley R, Leahy AL, Kelly CJ, Agha A, Thompson CJ, et al: Osteoprotegerin is higher in peripheral arterial disease regardless of glycaemic status. Thromb Res 126: e423-e427, 2010.

44. Hosbond SE, Poulsen TS, Diederichsen AC, Nybo M, Rasmussen LM and Mickley H: Osteoprotegerin as a marker of atherosclerosis: A systematic update. Scand Cardiovasc J 46: 203-211, 2012.

45. Kapetanios D, Karkos C, Giagtzidis I, Papazoglou K, Kiroplastis K and Spyridis C: Vascular calcification biomarkers and peripheral arterial disease. Int Angiol 35: 455-459, 2016.

46. Ye Z, Ali Z, Klee GG, Mosley TH Jr and Kullo IJ: Associations of candidate biomarkers of vascular disease with the ankle-brachial index and peripheral arterial disease. Am J Hypertens 26: 495-502, 2013

47. Fahrleitner-Pammer A, Obernosterer A, Pilger E, Dobnig H, Dimai HP, Leb G, Kudlacek S and Obermayer-Pietsch BM: Hypovitaminosis D, impaired bone turnover and low bone mass are common in patients with peripheral arterial disease. Osteoporos Int 16: 319-324, 2005.

48. Mikhaylova L, Malmquist J and Nurminskaya M: Regulation of in vitro vascular calcification by BMP4, VEGF and Wnt3a. Calcif Tissue Int 81: 372-381, 2007.

49. He XW, Wang E, Bao YY, Wang F, Zhu M, Hu XF and Jin XP: High serum levels of sclerostin and Dickkopf-1 are associated with acute ischaemic stroke. Atherosclerosis 253: 22-28, 2016.

50. Krishna SM, Seto SW, Jose RJ, Li J, Morton SK, Biros E, Wang Y, Nsengiyumva V, Lindeman JH, Loots GG, et al: Wnt signaling pathway inhibitor sclerostin inhibits angiotensin II-induced aortic aneurysm and atherosclerosis. Arterioscler Thromb Vasc Biol 37: 553-566, 2017.

51. Kim KM, Lim S, Moon JH, Jin H, Jung KY, Shin CS, Park KS, Jang $\mathrm{HC}$ and Choi SH: Lower uncarboxylated osteocalcin and higher sclerostin levels are significantly associated with coronary artery disease. Bone 83: 178-183, 2016.

52. Gaudio A, Fiore V, Rapisarda R, Sidoti MH, Xourafa A, Catalano A, Tringali G, Zanoli L, Signorelli SS and Fiore CE: Sclerostin is a possible candidate marker of arterial stiffness: Results from a cohort study in Catania. Mol Med Rep 15: 3420-3424, 2017. 
53. Popovic DS, Mitrovic M, Tomic-Naglic D, Icin T, Bajkin I, Vukovic B, Benc D, Zivanovic Z, Kovacev-Zavisic B and Stokic E: The Wnt/ $\beta$-catenin signalling pathway inhibitor sclerostin is a biomarker for early atherosclerosis in obesity. Curr Neurovasc Res 14: 200-206, 2017.

54. Morales-Santana S, García-Fontana B, García-Martín A Rozas-Moreno P, García-Salcedo JA, Reyes-García R and Muñoz-Torres M: Atherosclerotic disease in type 2 diabetes is associated with an increase in sclerostin levels. Diabetes Care 36: $1667-1674,2013$
55. Gaudio A, Privitera F, Pulvirenti I, Canzonieri E, Rapisarda R and Fiore CE: The relationship between inhibitors of the Wnt signalling pathway (sclerostin and Dickkopf-1) and carotid intima-media thickness in postmenopausal women with type 2 diabetes mellitus. Diab Vasc Dis Res 11: 48-52, 2014.

56. Saag KG, Petersen J, Brandi ML, Karaplis AC, Lorentzon M, Thomas T, Maddox J, Fan M, Meisner PD and Grauer A: Romosozumab or alendronate for fracture prevention in women with osteoporosis. N Engl J Med 377: 1417-1427, 2017. 